\title{
Limiting Behavior for Competing Species
}

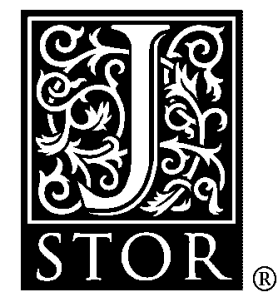

S. B. Hsu

SIAM Journal on Applied Mathematics, Vol. 34, No. 4. (Jun., 1978), pp. 760-763.

Stable URL:

http://links.jstor.org/sici?sici=0036-1399\%28197806\%2934\%3A4\%3C760\%3ALBFCS\%3E2.0.CO\%3B2-I

SIAM Journal on Applied Mathematics is currently published by Society for Industrial and Applied Mathematics.

Your use of the JSTOR archive indicates your acceptance of JSTOR's Terms and Conditions of Use, available at

http://www.jstor.org/about/terms.html. JSTOR's Terms and Conditions of Use provides, in part, that unless you have obtained prior permission, you may not download an entire issue of a journal or multiple copies of articles, and you may use content in the JSTOR archive only for your personal, non-commercial use.

Please contact the publisher regarding any further use of this work. Publisher contact information may be obtained at http://www.jstor.org/journals/siam.html.

Each copy of any part of a JSTOR transmission must contain the same copyright notice that appears on the screen or printed page of such transmission.

The JSTOR Archive is a trusted digital repository providing for long-term preservation and access to leading academic journals and scholarly literature from around the world. The Archive is supported by libraries, scholarly societies, publishers, and foundations. It is an initiative of JSTOR, a not-for-profit organization with a mission to help the scholarly community take advantage of advances in technology. For more information regarding JSTOR, please contact support@jstor.org. 


\title{
LIMITING BEHAVIOR FOR COMPETING SPECIES*
}

\author{
S. B. HSU†
}

\begin{abstract}
Two competition models concerning $n$ species consuming a single, limited resource are discussed. One is based on the Holling-type functional response and the other on the Lotka-Volterra-type. The focus of the paper is on the asymptotic behavior of solutions. LaSalle's extension theorem of Lyapunov stability theory is the main tool.
\end{abstract}

1. Introduction. This article is concerned with the limiting behavior, as $t \rightarrow+\infty$, for the solutions of the systems

$$
\begin{aligned}
& S^{\prime}(t)=\left(S^{(0)}-S(t)\right) D-\sum_{i=1}^{n} \frac{k_{i} x_{i}(t) S(t)}{a_{i}+S(t)} \\
& x_{i}^{\prime}(t)=\frac{m_{i} x_{i}(t) S(t)}{a_{i}+S(t)}-D_{i} x_{i}(t), \quad i=1, \cdots, n,
\end{aligned}
$$

where $S^{(0)}, D, k_{i}, a_{i}, m_{i}, D_{i}$ are positive, and

$$
\begin{aligned}
& S^{\prime}(t)=\gamma S(t)\left(1-\frac{S(t)}{K}\right)-\sum_{i=1}^{n} k_{i} x_{i}(t) S(t), \\
& x_{i}^{\prime}(t)=\alpha_{i} x_{i}(t)\left(S(t)-\beta_{i}\right), \quad i=1, \cdots, n,
\end{aligned}
$$

where $\gamma, K, k_{i}, \alpha_{i}, \beta_{i}$ are positive. Only the positive solutions are analyzed, because they are of realistic interest.

The system (A) describes $n$ species, with populations $x_{i}, i=1, \cdots, n$, and death rates $D_{i}$, competing for a single, limited resource $S$. This generalizes the model in [2] by allowing species-specific death rates. The species are assumed to feed on the resource with a saturating functional response to the resource density. Specifically, we assume that Michaelis-Menten kinetics or the Holling "disc" model describe how feeding rates and birth rates change with increasing resource density. Close parallels of this model in nature are e.g. the planktonic communities of unicellular algae in lakes and oceans. The species receive nutrient input from streams draining eroding water sheds or continental margins, and in lakes from nutrient regeneration during spring and fall overturn. For a more detailed biological background, we refer to [2].

The system (B) which is a generalization of the model given by MacArthur [5], has been discussed by Leung [4]. This competition model is based on Lotka-Volterra dynamics. It is also applicable to the economic study of $n$ groups exploiting a single life resource.

The mathematical feature of this paper is to apply LaSalle's extension theorem of Lyapunov stability theory ([1] or [3]). This technique allows us to generalize the results in [2] and to give simple, elegant proofs.

2. LaSalle's extensions theorem. We note the following definition and the theorem of LaSalle [3] which will be used in $\S \S 3$ and 4. Let $(I): x^{\prime}=f(x)$ be a system of differential equations. The vector-valued function $f(x)$ is continuous in $x$ for $x \in \bar{G}$ where $G$ is an open set in $R^{n}$. Let $V$ be a $C^{1}$ function on $R^{n}$ to $R$.

\footnotetext{
* Received by the editors April 19, 1977, and in revised form July 15, 1977.

$\dagger$ Department of Mathematics, University of Utah, Salt Lake City, Utah 84112.
} 
Definition. We say $V$ is a Lyapunov function in $G$ for $(I)$ if $\dot{V}=\operatorname{grad} V \cdot f \leqq 0$ on $G$.

Let $E=\{x \in \bar{G}: \dot{V}(x)=0\}$.

THEOREM. If $V$ is a Lyapunov function in $G$ for $(I)$, then each bounded solution $x(t) \subseteq G$ of $(I)$, approaches $M$ where $M$ is the largest invariant set in $E$.

3. Model of Holling's-type. In this section, we will discuss the limiting behavior of solutions for the system (A). First we note the following lemmas, omitting the proofs (see [2]).

LEMMA 3.1. The solutions $S(t), x_{i}(t), i=1, \cdots, n$ of (A) are positive and bounded.

LEMMA 3.2. Let $b_{i}=m_{i} / D_{i}, \lambda_{i}=a_{i} /\left(b_{i}-1\right), i=1, \cdots, n$. If

$$
\text { (i) } b_{i} \leqq 1
$$

or

$$
\text { (ii) } \lambda_{i}>S^{(0)} \text {, }
$$

then $\lim _{t \rightarrow \infty} x_{i}(t)=0$.

Our basic hypothesis is

$$
0<\lambda_{1} \leqq \lambda_{2} \leqq \cdots \leqq \lambda_{n}, \quad \lambda_{1}<S^{(0)} .
$$

The equations in (A) may be relabeled without loss of generality, so that the parameters $\lambda_{i}$ are nondecreasing in $i$. We note that $\left(\mathrm{H}_{n}\right)$ is more general than the hypothesis in [2] which excludes equality of this parameter for the first species.

THEOREM 3.3. Let $\left(\mathrm{H}_{n}\right)$ hold.

(i) If $0<\lambda_{1}<\lambda_{2} \leqq \cdots \leqq \lambda_{n}$, then the solutions of (A) satisfy

$$
\begin{aligned}
& \lim _{t \rightarrow \infty} S(t)=\lambda_{1}, \\
& \lim _{t \rightarrow \infty} x_{1}(t)=x_{1}^{*}=\frac{\left(S^{(0)}-\lambda_{1}\right)\left(a_{1}+\lambda_{1}\right) D}{k_{1} \lambda_{1}}, \\
& \lim _{t \rightarrow \infty} x_{i}(t)=0, \quad i=2,3, \cdots, n .
\end{aligned}
$$

(ii) If $0<\lambda_{1}=\cdots=\lambda_{j}<\lambda_{j+1} \leqq \cdots \leqq \lambda_{n}$, for some $j, 2 \leqq j \leqq n$, then the trajectory of (A) approaches $M$, where

$$
M=\left\{\left(\lambda_{1}, x_{1}, \cdots, x_{j}, 0, \cdots 0\right):\left(S^{(0)}-\lambda_{1}\right) D=\sum_{i=1}^{j} \frac{k_{i} \lambda_{i}}{\lambda_{i}+a_{i}} x_{i}, x_{i} \geqq 0, \quad i=1, \cdots, j\right\} .
$$

Proof. A rearrangement of (A) yields

$$
\begin{aligned}
& S^{\prime}(t)=\left(S^{(0)}-S(t)\right) D-\sum_{i=1}^{n} \frac{k_{i} x_{i}(t) S(t)}{a_{i}+S(t)}, \\
& x_{i}^{\prime}(t)=\left(m_{i}-D_{i}\right) \frac{S(t)-\lambda_{i}}{a_{i}+S(t)} x_{i}(t) .
\end{aligned}
$$

Let

$$
V\left(S, x_{1}, \cdots, x_{n}\right)=S-\lambda_{1}-\lambda_{1} \cdot \ln \left(\frac{S}{\lambda_{1}}\right)+c_{1}\left[\left(x_{1}-x_{1}^{*}\right)-x_{1}^{*} \cdot \ln \left(\frac{x_{1}}{x_{1}^{*}}\right)\right]+\sum_{i=2}^{n} c_{i} x_{i},
$$


and $G=\left\{\left(S, x_{1}, \cdots, x_{n}\right): S>0, \quad x_{i}>0, \quad i=1, \cdots, n\right\}$. Choose $c_{i}=k_{i} /\left(m_{i}-D_{i}\right), i=$ $1, \cdots, n$. Then the time derivative of $V$ computed along solutions of the differential equation is

$$
\dot{V}=\left(S-\lambda_{1}\right)\left[\frac{\left(S^{(0)}-S\right)}{S} D-\frac{k_{1} x_{1}^{*}}{a_{1}+S}\right]+\sum_{i=2}^{n} k_{i}\left(\lambda_{1}-\lambda_{i}\right) \frac{x_{i}}{a_{i}+S}
$$

or

$$
\dot{V}=\frac{\left(S-\lambda_{1}\right)^{2} D}{\left(a_{1}+S\right) S \lambda_{1}}\left(-\lambda_{1} S-a_{1} S^{(0)}\right)+\sum_{i=2}^{n} k_{i}\left(\lambda_{1}-\lambda_{i}\right) \frac{x_{i}}{a_{i}+S} \leqq 0 \quad \text { on } G .
$$

If $0<\lambda_{1}<\lambda_{2} \leqq \cdots \leqq \lambda_{n}$, then

$$
E=\left\{\left(\lambda_{1}, x_{1}, 0, \cdots, 0\right): x_{1} \geqq 0\right\}
$$

and the largest invariant set $M$ in $E$ is $\left\{\left(\lambda_{1}, x_{1}^{*}, 0, \cdots, 0\right)\right\}$. Hence (3.1) follows directly from Lemma 3.1 and LaSalle's theorem.

If $0<\lambda_{1}=\cdots=\lambda_{j}<\lambda_{j+1} \leqq \cdots \leqq \lambda_{n}$ for some $j, 2 \leqq j \leqq n$, then from (3.2) we have

$$
E=\left\{\left(\lambda_{1}, x_{1}, \cdots, x_{j}, 0, \cdots, 0\right): x_{1}, \cdots, x_{j} \geqq 0\right\}
$$

and

$$
M=\left\{\left(\lambda_{1}, x_{1}, \cdots, x_{j}, 0, \cdots, 0\right):\left(S^{(0)}-\lambda_{1}\right) D=\sum_{i=1}^{j} \frac{k_{i} \lambda_{1}}{a_{1}+\lambda_{1}} x_{i}, x_{i} \geqq 0, i=1, \cdots, j\right\} .
$$

Hence the trajectory approaches $M$.

4. Remark on the model of Lotka-Volterra. The arguments of $\S 3$ can be modified to give a short proof for the behavior of solutions of system (B), considered in [4].

We note the following lemmas which are easy to prove:

1) The solutions of the system (B) are positive and bounded. 2) If $K<\beta_{i}$, for any $i=1, \cdots, n$, then $\lim _{t \rightarrow \infty} x_{i}(t)=0$.

The basic hypothesis is

$$
0<\beta_{1} \leqq \beta_{2} \leqq \cdots \leqq \beta_{n}, \quad \beta_{1}<K .
$$

Using these lemmas and the Lyapunov function

$$
V\left(S, x_{1}, \cdots, x_{n}\right)=S-\beta_{1}-\beta_{1} \cdot \ln \left(\frac{S}{\beta_{1}}\right)+\frac{k_{1}}{\alpha_{1}}\left[\left(x_{1}-x_{1}^{*}\right)-x_{1}^{*} \cdot \ln \left(\frac{x_{1}}{x_{1}^{*}}\right)\right]+\sum_{i=2}^{n} \frac{k_{i}}{\alpha_{i}} x_{i},
$$

where $x_{i}^{*}=\left(\gamma / k_{1}\right)\left(1-\left(\beta_{i} / K\right)\right)$, one can show that $\dot{V}=-(\gamma / K)\left(S-\beta_{1}\right)^{2}+$ $\sum_{i=2}^{n}\left(\beta_{1}-\beta_{i}\right) k_{i} x_{i} \leqq 0$ on $G=\left\{\left(S, x_{1}, \cdots, x_{m}\right): S>0, x_{i}>0, i=1, \cdots, n\right\}$.

If $0<\beta_{1}<\beta_{2} \leqq \cdots \leqq \beta_{n}$, then $E=\left\{\left(\beta_{1}, x_{1}, 0, \cdots, 0\right): x_{1} \geqq 0\right\}$ and $M=$ $\left\{\left(\beta_{1}, x_{1}^{*}, 0, \cdots, 0\right)\right\}$.

If $0<\beta_{1}=\beta_{2}=\cdots=\beta_{j}<\beta_{j+1} \leqq \cdots \leqq \beta_{n}$ for some $j, 2 \leqq j \leqq n$, then $E=$ $\left\{\left(\beta_{1}, x_{1}, \cdots, x_{j}, 0, \cdots, 0\right): x_{i} \geqq 0, i \leqq j\right\}$ and $M=\left\{\left(\beta_{1}, x_{1}, \cdots, x_{j}, 0, \cdots, 0\right) \in E: \gamma(1-\right.$ $\left.\left.\left(\beta_{1} / K\right)\right)=\sum_{i=1}^{j} k_{i} x_{i}\right\}$.

Let $\Omega$ be the $w$-limit set of the trajectory $\left(S(t), x_{1}(t), \cdots, x_{n}(t)\right)$ with the initial values $S(0)=S_{0}, x_{i}(0)=x_{i 0}, 1 \leqq i \leqq n$. Let $k$ be an integer such that $\alpha_{k}=\min _{1 \leqq k \leqq j}\left\{\alpha_{i}\right\}$. Since $\beta_{1}=\cdots=\beta_{j}$, from (B) it follows that

$$
x_{i}(t)=x_{i 0} x_{k 0}^{-\alpha_{i} / \alpha_{k}}\left(x_{k}(t)\right)^{\alpha_{i} / \alpha_{k}}, \quad 1 \leqq i \leqq j .
$$


Hence

$$
\begin{aligned}
\Omega \subseteq\{ & \left(\beta_{1}, x_{1}, \cdots, x_{j}, 0, \cdots, 0\right) \in E: \gamma\left(1-\frac{\beta_{1}}{K}\right) \\
& \left.=\sum_{i=1}^{j} k_{i} x_{i 0} x_{k 0}^{-\alpha_{i} / \alpha_{k}} x_{k}^{\alpha_{i} / \alpha_{k}}, \quad x_{i}=x_{i 0} x_{k 0}^{-\alpha_{i} / \alpha_{k}} x_{k}^{\alpha_{i} / \alpha_{k}}, \quad 1 \leqq i \leqq j\right\} .
\end{aligned}
$$

From Theorem 1 in [4], there exists the unique positive root $x_{k}=\bar{x}_{k 0}$ for the equation

$$
\gamma\left(1-\frac{\beta_{1}}{K}\right)=\sum_{i=1}^{j} k_{i} x_{i 0} x_{k 0}^{-\alpha_{i} / \alpha_{k}} x_{k}^{\alpha_{k} / \alpha_{k}}
$$

By the assumption $\beta_{1}<K$, we have

$$
\Omega=\left\{\left(\beta_{1}, \bar{x}_{10}, \cdots, \bar{x}_{j 0}, 0, \cdots, 0\right)\right\}, \quad \text { where } \bar{x}_{i 0}=x_{i 0} x_{k 0}^{-\alpha_{i} / \alpha_{k}} \bar{x}_{k 0}^{\alpha_{i} / \alpha_{k}} .
$$

In either case, the results in [4] follow.

\section{REFERENCES}

[1] J. K. HALE, Ordinary Differential Equation, Wiley-Interscience, New York, 1969.

[2] S. B. Hsu, S. P. HubBell AND P. WALTMAN, A mathematical theory for single-nutrient competition in continuous cultures of micro-organisms, this Journal, 32 (1976), pp. 366-383.

[3] J. LASAlle, Some extension of Liapunov's second method, IRE Trans. Circuit Theory, CT-7 (1960), pp. 520-527.

[4] A. LEUNG, Limiting behavior for several interacting populations, Math. Biosci., 29 (1976), pp. 85-98.

[5] R. H. MACARTHUR, Geographical Ecology, Harper and Row, New York, 1972. 